\title{
International Committee on Systematic Bacteriology Subcommittee on the Taxonomy of Pasteurellaceae and Related Organisms
}

\author{
Minutes of the Meeting, 6 July 1994, Prague, Czech Republic
}

Minute 1. Call to order. The Chairman, Walter Mannheim, called the meeting to order at 1300 on 6 July 1994.

Minute 2. Record of attendance. The members present were M. Bisgaard, P. Blackall, F. E. Dewhirst, F. Escande, W. Frederiksen (Secretary), M. Kilian, W. Mannheim (Chairman), and R. Mutters. Apologies for absence were received from E. L. Biberstein, G. R. Carter, J. Nicolet, R. Nielsen, and K. R. Rhoades.

Minute 3. Minutes of the previous meeting. The minutes of the previous meeting held in Prague, Czech Republic, in 1992 had been published, and no further comments were received.

Minute 4. Open meeting. It was decided to have the first part of the meeting an open meeting (minutes 5 to 11). Two guests were present.

Minute 5. New genera and species in the Pasteurellaceae. W. Mannheim gave an overview of new genera and species and pointed out taxa that might deserve recognition as new genera; however, the pattern derived from rRNA sequencing data by the nearest-neighbor-joining method (especially the studies of F. E. Dewhirst and B. J. Paster) had revealed some unexpected groupings, and it was felt that confirmation by other taxometric procedures and further chemotaxonomic information were needed. H. J. Busse described the results of studies in which polyamines were used as taxonomic tools. This seemed to provide some of the information needed, but more strains should be included.

Minute 6. The Pasteurella haemolytica complex. M. Bisgaard described studies on the ribotypes of Pasteurella haemolytica biovar 1 and on the so-called third taxon.

Minute 7. The Pasteurella aerogenes complex. M. Bisgaard described the phenotypic and genotypic results of a collaboratory study on Pasteurella aerogenes. Further studies are needed to redefine this species.

Minute 8. Principles for description of new taxa. W. Frederiksen had circulated a draft of principles for description of new taxa and will write a draft aimed at the Pasteurellaceae.

Minute 9. Correct and valid names. F. Escande mentioned some recent publications in which invalid names were used. The subcommittee supported the view that only approved or validated names should be used and the view that invalid names should be put in quotation marks. If two validly published genus names exist, one of them may be given in parentheses.

Minute 10. Questionnaire for Pasteurella infections. F. Es- cande has published results of a compilation of clinical information accompanying strains sent for identification to the French reference laboratory at the Institut Pasteur in Paris, France. The subcommittee agreed that this was a very useful activity and that other countries should be encouraged to do similar work. P. Blackall stated that he would contact the reference laboratory in Australia.

Minute 11. Formation of working groups. W. Mannheim proposed that a working group on delineation of genera should be formed. This working group should consider not only chemotaxonomy of macromolecules, but also the practicability of taxonomic proposals. M. Bisgaard, H. J. Busse, F. L. Dewhirst, and R. Mutters agreed to form a group and to establish immediate contact. Microbiologists with taxonomic interest in this area should contact the subcommittee.

Minute 12. Election of officers. The Secretary had circulated a ballot on which there were two candidates for Chairman and two candidates for Secretary. A total of 11 ballots were returned. There were six votes for F. E. Dewhirst to be Chairman and four votes for P. Blackall. There were six votes for M. Bisgaard to be Secretary and four votes for R. Mutters. The Chairman welcomed the two new officers. M. Bisgaard and F. E. Dewhirst thanked the retiring Chairman and Secretary.

Minute 13. Current membership. K. R. Rhoades had retired and wanted to leave the subcommittee. He had suggested R. B. Rimler as a new member. The ballot results were 10 votes for R. B. Rimler and no votes against. G. R. Carter and E. L. Biberstein had indicated that they would like to be considered emeritus members. It was felt that $\mathrm{H}$. J. Busse would be a valuable member of the subcommittee, and he was unanimously accepted as a new member. As of October 1994 the members of the subcommittee are E. L. Biberstein, M. Bisgaard (Secretary), P. Blackall, H. J. Busse, G. R. Carter, F. E. Dewhirst (Chairman), F. Escande, W. Frederiksen, M. Kilian, W. Mannheim, R. Mutters, J. Nicolet, R. Nielsen, and R. B. Rimler.

Minute 14. Other matters. The next meeting of the subcommittee will be in Jerusalem in 1996 at the next International Union of Microbiological Societies congress.

Minute 15. Adjournment. The meeting was adjourned at 1600 on 6 July 1994.

Wilhelm Frederiksen, Secretary 